Supplement of Geosci. Model Dev., 12, 2571-2585, 2019

https://doi.org/10.5194/gmd-12-2571-2019-supplement

(C) Author(s) 2019. This work is distributed under

the Creative Commons Attribution 4.0 License.

(c) (1)

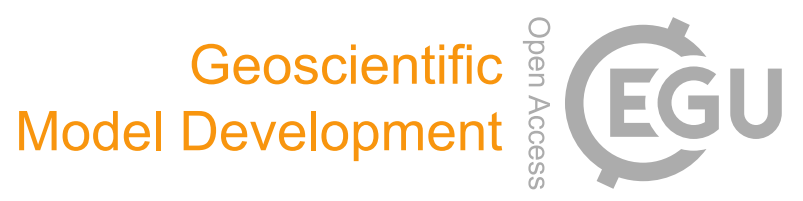

Supplement of

\title{
Quantitative stratigraphic analysis in a source-to-sink numerical framework
}

Xuesong Ding et al.

Correspondence to: Xuesong Ding (xuesong.ding@sydney.edu.au)

The copyright of individual parts of the supplement might differ from the CC BY 4.0 License. 


\section{Model setup}

pyBadlands is an open-source landscape evolution model based on a triangulated irregular networks (TIN) discretization. It can be used to simulate landscape dynamics over regional to continental scales and thousands to millions of years. In

5 addition to fundamental geomorphological processes, pyBadlands simulates sedimentary basin filling and the formation of stratal architectures in response to the interplay between multiple driving mechanisms, such as climate, sea level change, tectonics, and sediment transport.

Different fluvial incision laws can be used to describe sediment erosion, transport and deposition, including detachmentlimited stream power law, and sediment flux dependent bedrock incision laws (Salles et al., 2018). In this study, we use a single

flow direction and detachment-limited stream power law which takes the form of:

$$
E=\epsilon A^{m}(\nabla Z)^{n}
$$

where the erosion rate $E$ is modelled as a power function of contributing drainage area $A$ and topographic gradient $\nabla Z$. The erodibility coefficient $\epsilon$ is equal to $2.0 \times e^{-7} \mathrm{yr}^{-1}$, and is assumed to be uniform temporally and spatially over the whole domain. The drainage area $A$ is related to surface water discharge per unit width through net precipitation (Tucker and Hancock, 2010). The parameters $m$ and $n$ are set equal to 0.5 and 1.0, respectively (Salles and Hardiman, 2016).

pyBadlands makes it possible to simulate hillslope processes using either linear or non-linear diffusion laws (Salles et al., 2018). Sediment transport in marine realm is defined based on a diffusion law that has been widely used to simulate sedimentary systems behaviour over large spatial and temporal scale (Paola et al., 1992; Granjeon and Joseph, 1999; Meijer, 2002). Here, hillslope processes are described using a simple downslope creep law where induced sediment transport depends linearly on topographic gradient:

$$
\frac{\partial Z}{\partial t}=\kappa \nabla^{2} Z
$$

the diffusion coefficient $\kappa$ is scale-dependent and its value depends on lithology and mean precipitation (Chen et al., 2014). In our example, the parameter $\kappa$ is equal to $0.01 \mathrm{~m}^{2} / \mathrm{yr}$ for subaerial sediments, to $0.05 \mathrm{~m}^{2} / \mathrm{yr}$ for marine sediments, and to 10 $\mathrm{m}^{2} / \mathrm{yr}$ for river transported sediment in marine environment. The diffusion coefficient $\kappa$ is set larger in marine environment to account for sediments reworking by waves and/or currents. Slow creeping coefficients are usually in the range of $10^{-4}$ $\mathrm{m}^{2} / \mathrm{yr}$ to $10^{-2} \mathrm{~m}^{2} / \mathrm{yr}$, while fast fluvial transport coefficients are often set between $10^{2} \mathrm{~m}^{2} / \mathrm{yr}$ and $10^{4} \mathrm{~m}^{2} / \mathrm{yr}$ (Flemings and Jordan, 1989; Avouac and Burov, 1996). Therefore, our defined coefficients for subaerial and marine environments correspond to slow creep processes. A critical depositional slope of $0.001 \mathrm{~m} / \mathrm{m}$ is imposed in alluvial plain regions. Once sediments enter the marine realm, they are transported using a multiple flow directions approach and fill the available accommodation until sediment supply runs out.

\section{Rate of sediment supply}

We calculated the total eroded volume at $0.1 \mathrm{Myr}$ intervals over the whole domain (blue solid curve in Fig. S1a) and on the cross-section (blue dashed curve in Fig. S1a) to estimate the rate of sediment supply change ( $\delta S$ in $\mathrm{km}^{3} / \mathrm{Myr}$ ) through time. We find that the rate of sediment supply increases as the channel slope steepens (a direct consequence of the stream power law used in our study), then stabilises after $20 \mathrm{Myr}$. Three decreases in $\delta S$ over the whole domain are recorded from $7.8 \mathrm{Myr}$ to 9.5 Myr, 17.8 Myr to $20 \mathrm{Myr}$, and 27.5 Myr to $30 \mathrm{Myr}$ (light gray boxes in Fig. S1a). Decreases in $\delta S$ also occur on the crosssection but they are shorter lived. These events consistently occur during shoreline transgression which induces less exposed shelf area to be incised. Comparing the eroded volume for different zones (e.g. source area and transfer zone - Fig. S1a) shows that the source area exhibits an initial increase in eroded volume followed by a stabilisation period after $20 \mathrm{Myr}$ (orange solid curve in Fig. S1a). The transfer zone presents similar coincidental patterns of decrease in sediment supply (purple solid curve with blue solid curve in Fig. S1a). Erosion and deposition rates from 8 Myr to 9 Myr (Fig. S1b), 18 Myr to 19 Myr (Fig. S1c) 

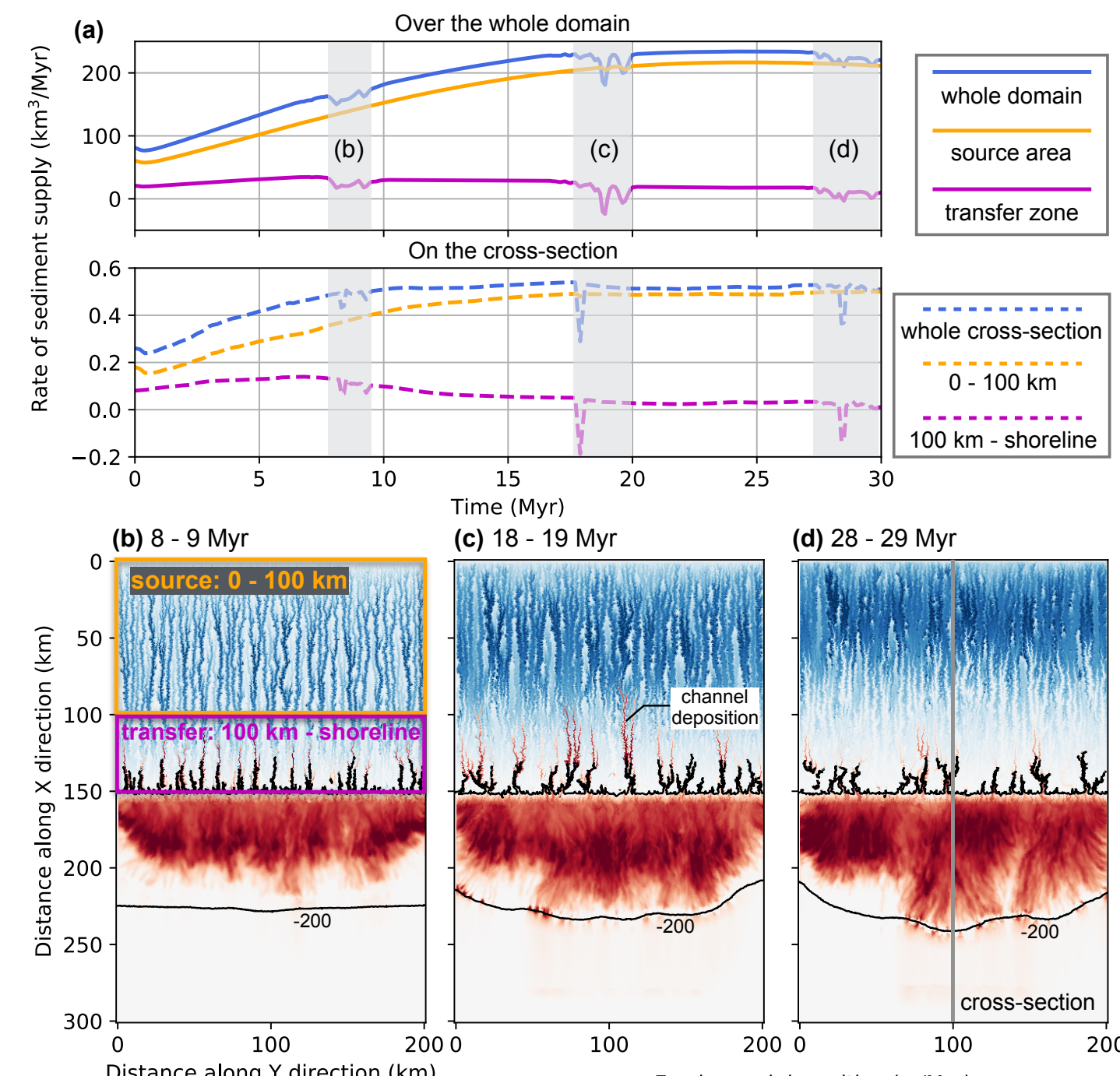

(c) 18 - $19 \mathrm{Myr}$

(d) $28-29 \mathrm{Myr}$
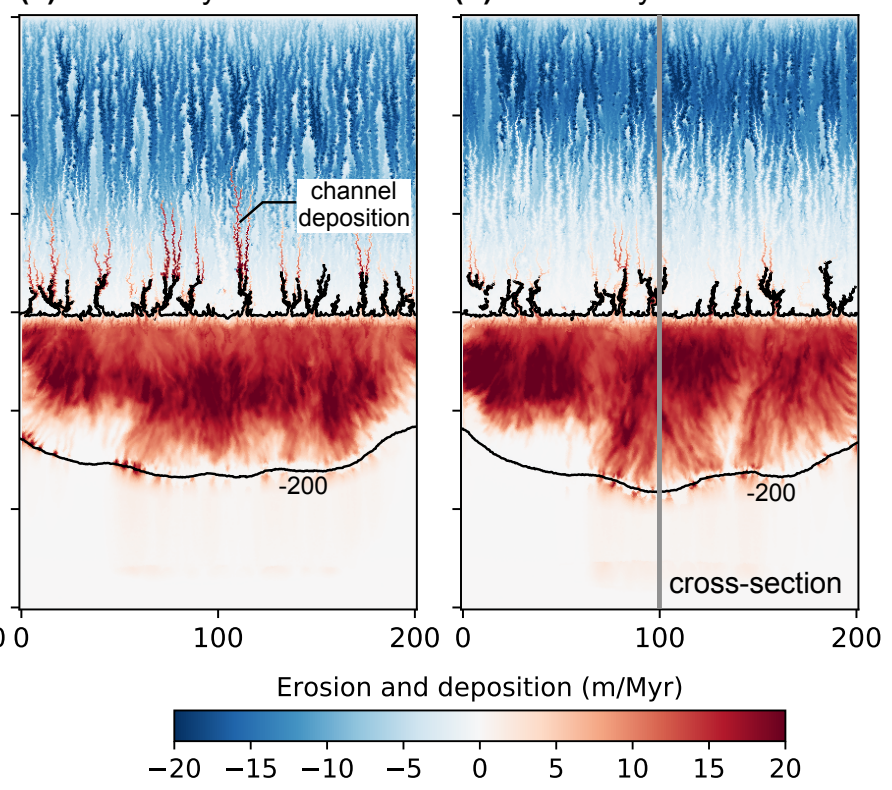

Figure S1. (a) Rate of sediment supply defined as the eroded volume calculated in $0.1 \mathrm{Myr}$ increments over the entire domain, the source area and the transfer zone (top panel), as well as along the entire cross-section and the source and transfer areas along the cross-section (bottompanel). See Fig. 3f and (d) for the location of the cross-section. The light gray boxes in (a) highlight episodic decreases in eroded volume. The erosion and deposition from $8 \mathrm{Myr}$ to $9 \mathrm{Myr}$, from $18 \mathrm{Myr}$ to $19 \mathrm{Myr}$, and from $28 \mathrm{Myr}$ to $29 \mathrm{Myr}$ are presented in (b-d) shows that channel deposition in response to sea level rise occurs during the three episodic decreases in rate of sediment supply.

and $28 \mathrm{Myr}$ to $29 \mathrm{Myr}$ Fig. S1d), reveal that this decrease in erosion volume is also related to downstream channel deposition across the transfer zone. We attribute this autogenic behaviour to the adjustment of river profiles to base level rise. Negative $\delta S$ occurs at around $18 \mathrm{Myr}$ and $28 \mathrm{Myr}$ (Fig. S1a), which reflects greater deposition than erosion. 


\section{References}

Avouac, J.-P. and Burov, E.: Erosion as a driving mechanism of intracontinental mountain growth, Journal of Geophysical Research: Solid Earth, 101, 17 747-17 769, 1996.

Chen, A., Darbon, J., and Morel, J.-M.: Landscape evolution models: A review of their fundamental equations, Geomorphology, 219, 68-86, 2014.

Flemings, P. B. and Jordan, T. E.: A synthetic stratigraphic model of foreland basin development, Journal of Geophysical Research: Solid Earth, 94, 3851-3866, 1989.

Granjeon, D. and Joseph, P.: Concepts and applications of a 3-D multiple lithology, diffusive model in stratigraphic modeling, 1999.

Meijer, X.: Modelling the drainage evolution of a river-shelf system forced by Quaternary glacio-eustasy, Basin Research, 14, 361-377, 2002.

Paola, C., Heller, P. L., and Angevine, C. L.: The large-scale dynamics of grain-size variation in alluvial basins, 1: Theory, Basin Research, 4, 73-90, 1992.

Salles, T. and Hardiman, L.: Badlands: An open-source, flexible and parallel framework to study landscape dynamics, Computers \& Geosciences, 91, 77-89, 2016.

15 Salles, T., Ding, X., and Brocard, G.: pyBadlands: A framework to simulate sediment transport, landscape dynamics and basin stratigraphic evolution through space and time, PloS one, 13, e0195 557, 2018.

Tucker, G. E. and Hancock, G. R.: Modelling landscape evolution, Earth Surface Processes and Landforms, 35, 28-50, 2010. 